\title{
O estudo do processo criativo do poema The Armadillo a partir de categorias espaciais
}

\author{
The creative process study of the poem The Armadillo based on spatial categories
}

\author{
Elisabete da Silva Barbosa ${ }^{1}$
}

\begin{abstract}
RESUMO: O estudo da espacialidade a partir de documentos relativos a um processo criativo permite um melhor entendimento do signo no contexto de seu nascimento, momento em que a linguagem é burilada para tornar-se um constructo literário. Trata-se de um estudo que permite não apenas que se acompanhe o desenvolvimento do signo linguístico, mas também que se observem as relações que o processo criativo estabelece com o mundo que cerca o escritor. Propor uma interdisciplinaridade entre o processo de criação e categorias provindas da geografia - como a de território e a de espaço - significa entender a ação de criar como aquela que acontece em um local específico - seja no ateliê do artista, seja na materialidade que, por excelência, dá lugar à inventividade humana. No que diz respeito à gênese dos poemas de Elizabeth Bishop (1911-1979), grande parte das imagens geradoras identificadas é motivada por lugares visitados ou habitados pela autora. $\mathrm{O}$ espaço, nesse contexto, contribui para a produção de imagens que alimentam o seu processo criativo. Do mesmo modo, o novo texto gera significações singulares para o espaço retratado pela linguagem.
\end{abstract}

Palavras-chave: Processo de criação; Espacialidade; Elizabeth Bishop.

ABSTRACT: The study of spatiality of documents, which testify a creative process, leads to a better understanding of the sign in the context of its birth, when the language is refined to become a literary construct. It is a study that allows not only the accompaniment of the linguistic sign development, but also the observation of the relations creative process establishes with the world that surrounds the author. To propose an interdisciplinary study between the creation process and categories belonging to the geographical universe such as space means to understand the creation action as one that happens in a specific place - in the artist atelier or in the materiality, which gives a form to the human inventiveness. In what concern to the genesis Elizabeth Bishop's (1911-1979) poems, the motivation of many generating images identified are in places visited or habited by the author. The space, in this context, contributes to the production of images that feed her creative process. Likewise, the new text engenders singular meanings to the space depicted by language.

Keywords: Creation process; Spatiality; Elizabeth Bishop.

Nos últimos anos, temos observado um crescente interesse por questões relativas à representação dos espaços, ao que se pode relacionar o que Soja (1993 [1989]) tem denominado virada espacial - uma mudança no modo de conduzir as pesquisas no campo das

\footnotetext{
${ }^{1}$ Doutora em Literatura e Cultura pela Universidade Federal da Bahia (2016). Mestre em Linguagens pela Universidade do Estado da Bahia (2010). Graduada em Língua Estrangeira pela Universidade Federal da Bahia (2002). Professora da Universidade do Estado da Bahia. E-mail: elisabete_barbosa@hotmail.com
} 
ciências humanas, que traz a espacialidade para o centro das discussões a partir do final do século XX.

Ao identificar em textos de Foucault "uma abertura da história para a geografia interpretativa", Soja (1993 [1989], p. 27), propõe um estudo que leve em consideração a interação da sucessão temporal com a simultaneidade espacial. Considerar o espaço como categoria de análise passa a ser assunto de crescente interesse nas diversas áreas, pois,

[...] a inquietação de hoje se refere fundamentalmente ao espaço, sem dúvida muito mais que ao tempo; o tempo provavelmente só aparece como um dos jogos de distribuição possíveis entre os elementos que se repartem no espaço (FOUAULT, 2009 [1984], p. 413).

Desde então, a espacialidade vem se imiscuindo no discurso crítico, primeiramente como metáfora para, mais tarde, ser considerada como uma possível categoria de análise. $\mathrm{O}$ mundo social muda, e assim as formas tradicionais de interpretar os seus fenômenos tornamse insuficientes. É por isso que, ao lado da noção da linguagem como um constructo histórico, surge uma concepção diversa que a percebe, também, como elemento material atuante na produção e modificação de lugares e territórios.

O estudo da espacialidade a partir de documentos resultantes de um processo criativo permite entender o signo no contexto de seu nascimento, momento em que a linguagem é burilada para tornar-se um constructo literário. Trata-se de um estudo que permite não apenas acompanhar o desenvolvimento do signo, mas também observar as relações que o processo criativo estabelece com o mundo que cerca o escritor.

Propor uma interdisciplinaridade entre o processo de criação e categorias provindas da geografia - como a de território e a de espaço - significa entender a ação de criar como aquela que acontece em um local específico - seja no ateliê do artista, seja na materialidade que dá lugar à inventividade humana -, relacionada a diversos trânsitos do sujeito pelas dimensões mais diversas, aquelas das quais seja possível apossar-se.

O manuscrito moderno é um objeto material que conduz a um melhor entendimento de uma obra literária e, mais especificamente, à dinâmica que lhe deu origem. Trata-se de objeto que guarda as marcas de um processo escritural traduzido em rasuras de diversos tipos, quais sejam, os acréscimos, as supressões, os deslocamentos ou, ainda, os avanços e retrocessos. Para representar esses movimentos e realizar uma transcrição semidiplomática, adotamos os operadores utilizados por Anastácio (1999):

[ ] eliminação

$<>$ acréscimo 
$>$ acréscimo à margem direita

$<<$ acréscimo à margem esquerda (ANASTÁCIO, 1999, p. 31).

Sentimos, ainda, a necessidade de dispor de outros operadores que dessem conta de movimentos ou de dificuldades encontradas no momento da transcrição, de modo que acrescentamos:

a) Cada palavra conjecturada aparece acompanhada por um asterisco*;

b) Palavras ou estrofes suprimidas por deslocamento são isoladas por setas, indicativas da direção onde o termo ou trecho deve aparecer.

$\uparrow$ deslocamento $\uparrow$ para cima

$\downarrow$ deslocamento $\downarrow$ para baixo

$\leftarrow$ deslocamento $\leftarrow$ para a esquerda

$\rightarrow$ deslocamento $\rightarrow$ para a direita

O fragmento deslocado reaparece no novo local em cor cinza, fazendo alusão àquela presença virtual.

c) Uma palavra ilegível será indicada por X. Na impossibilidade de leitura de mais de uma palavra em sequência, cada uma delas será representada pelo mesmo símbolo. (BARBOSA, 2016, p. 57).

Tais operações, de ordem genética, são entendidas como vestígios de um movimento criador cujos limites não se pode precisar, mas que revelam alguns dos mecanismos mentais que dizem respeito ao processo estudado. Por funcionar como a porta de acesso ao espaço da criação, o manuscrito moderno favorece a realização de estudos sobre o processo criativo de um escritor.

A respeito dessa materialidade, Grésillon (2007 [1994]) afirma que, por meio dela, o geneticista entra em contato com materiais que são, a princípio, peças de arquivo, mas que funcionam como "testemunhas materiais de uma dinâmica criadora" (GRÉSILLON, 2007 [1994], p. 29). Trata-se de um estudo que se apoia na observação dos traçados na página, os quais conduzem à construção de "hipóteses sobre os caminhos percorridos pela escritura e sobre as significações possíveis desse processo de criação" (GRÉSILLON, 2007 [1994], p. 29).

Tomando como referência o modo como se tem conduzido as pesquisas em Crítica Genética, podemos afirmar que a dimensão temporal de um ato criativo somente pode ser acessada a partir do estabelecimento de relações entre os vestígios encontrados. Revela-se, pois, na materialidade do processo. Isso porque o signo linguístico, de natureza espacial, pode ser inscrito em um "espaço visual e ter existência continuada nesse espaço" (BOLTER, 2001, p. 16).

Ao lado da materialidade do processo de criação mais palpável, possuidora de forma, textura, espessura, cor etc. - elementos que, em um primeiro plano, dizem respeito ao espaço -, há ainda uma espacialidade inerente à própria linguagem já anunciada por Foucault (2000 
[1964]). Nesse contexto, o material linguístico somente pode ser considerado signo porque seu ser está diretamente relacionado ao espaço, afirmação proferida em palestra cujo texto foi publicado pela primeira vez em 1964, intitulada Linguagem e literatura:

\begin{abstract}
De fato, o que se está descobrindo hoje, por muitos caminhos diferentes, além do mais quase todos empíricos, é que a linguagem é espaço. Tinha-se esquecido isso simplesmente porque a linguagem funciona no tempo, é a cadeia falada que funciona para dizer o tempo. Mas a função da linguagem não é o seu ser: se sua função é tempo, seu ser é espaço. Espaço porque cada elemento da linguagem só tem sentido em uma rede sincrônica. Espaço porque o valor semântico de cada palavra ou de cada expressão é definido por referência a um quadro, a um paradigma. Espaço porque a própria sucessão dos elementos, a ordem das palavras, as flexões, a concordância entre as palavras, ao longo da cadeia falada obedecem, mais ou menos, às exigências simultâneas, arquitetônicas, por conseguinte espaciais, da sintaxe. Espaço, enfim, porque, de modo geral, só há signos significantes, com seu significado por leis de substituição, de combinação de elementos, portanto, por uma série de operações definidas em um conjunto, por conseguinte, em um espaço. Durante muito tempo, praticamente até hoje, confundiram-se as funções anunciadoras e recaptuladoras do signo que são funções temporais, com o que the permitia ser signo. A palavra de Deus, que faz com que os signos do fim do mundo sejam os signos do fim do mundo, não é temporal; ela pode se manifestar no tempo, mas é eterna, sincrônica com relação a cada um dos signos que significam algo (FOUCAULT, 2000 [1964], p. 168, grifo nosso).
\end{abstract}

O ser da linguagem, não mais desvelado como tempo (categoria associada às funções anunciadora e recaptuladora do signo), passa a ser identificado com o espaço. Assim, com base na concepção foucaultiana acerca da natureza do signo e nos procedimentos adotados pelo geneticista, podemos afirmar que a compreensão de uma obra se dá através de uma linguagem que se espacializa e, aqui, nos referimos a signos projetados sobre a folha em branco.

A obra literária, constituída de material linguístico, não pode ser confundida com o espaço da cultura ou da obra da qual se alimenta; faz-se necessário pensar que existe uma espacialidade inerente à própria linguagem, encontrada "na folha em branco que, por sua própria natureza, constitui e abre um certo espaço, não raro muito complexo" (FOUCAULT, 2000 [1964], p. 171). O signo ali inscrito é pensado como materialidade que se esconde em suas diversas camadas semiológicas, as quais se mostram no "lugar onde elas se espacializaram" (FOUCAULT, 2000 [1964], p. 173).

Nesse contexto, o espaço do papel - e, por conseguinte, o manuscrito de trabalho do escritor - mostra-se tanto aberto quanto fechado. Ao fazemos uma analogia com os materiais relativos à gênese textual, podemos afirmar que a primeira aparência do manuscrito é estática e fechada. No entanto, abre-se ao olhar do crítico, que intenciona desvelar alguns dos 
possíveis caminhos trilhados pela mente criadora a partir dos mecanismos mentais que a rasura deixa transparecer.

Desse modo, podemos afirmar que o crítico, ao seguir as pistas deixadas pelo escritor, as estuda em duas etapas: primeiro, segue uma trajetória que tende a encontrar uma estabilidade para o signo, no sentido de transcrevê-lo e, eventualmente, apresentar uma edição genética. Busca recuperar, nessa etapa, a topografia da página e decifrar os signos ali presentes.

Tal organização espacial propicia uma segunda etapa, a da interpretação da reescritura de cada signo paradigmaticamente, o que pode ser considerado uma via para o entendimento do signo em sua função anunciadora, isto é, temporal, da construção de um objeto ficcional. Possibilita, portanto, o estudo da obra a partir de sua dimensão espacial, aquela que dá acesso ao movimento da obra, ou seja, à sua temporalidade. Ou, ainda, podemos dizer que é a partir da análise dos signos como expressões documentais de cada etapa de escritura que se pode realizar o encadeamento da sucessividade do signo reescrito e, assim, compreender a criação em ato.

Fazer uma abordagem da obra de Bishop por meio de conceitos e metáforas espaciais tem respaldo no que diz Salles (2006, p. 15) sobre os instrumentais teóricos, os quais “[...] devem ser convocados de acordo com as necessidades do andamento das reflexões, para que os documentos dos artistas não se transformem em meras ilustrações das teorias" (SALLES, 2006, p. 15).

Estudo da gênese de The Armadillo

No que diz respeito à gênese dos poemas de Elizabeth Bishop, grande parte das imagens geradoras identificadas é motivada por lugares visitados ou habitados pela autora, a exemplo de The Armadillo (1957), em que o cenário da festa de São João no Brasil é retratado a partir da perspectiva dos animais habitantes da floresta

Com o estudo desse poema, pudemos observar que as experiências de Bishop em diversos espaços contribuem para a produção de imagens que alimentam o seu processo criativo. Por outro lado, o novo texto gera significações singulares para o espaço retratado pela linguagem.

Para ilustrar tal situação, realizamos um estudo crítico de The Armadillo, escrito e publicado pela primeira vez no ano de 1957, no qual Bishop adota um dos temas que lhe é 
caro, a presença de animais e de paisagens. Trata-se de um poema descritivo, cujo processo criativo apresenta imagens desenvolvidas de forma binária, o que Anastácio (1999) identifica como um dos principais eixos do pensamento de Bishop, o dialético. No poema, a beleza dos balões recebe destaque nas cinco primeiras estrofes, para, nas cinco finais, contar o drama vivido pelos animais da floresta.

O tatu ocupa lugar privilegiado, figurando no título do poema. Além desse animal, são retratados um par de corujas e um filhote de coelho. Segundo Goldenshon (1992, p. 6, tradução nossa), Bishop usa uma linguagem "filtrada por uma sensibilidade estética de longo alcance que responde, primeiro, aos estímulos da paisagem, com destaque para a fauna e a flora". Tais temas costumam aparecer no projeto escritural de Bishop primeiro em prosa para, somente depois, assumirem o formato de poemas. Costello (1991, p. 207) observa que os elementos presentes nesse poema já vinham aparecendo nos papéis da autora, especialmente nas cartas.

Dois desses animais fazem parte de um fragmento escrito por Bishop, intitulado The Owl's Journey: o coelho e a coruja. Esse fragmento tem como suporte um caderno no qual a autora costumava anotar os seus sonhos e que remonta ao período em que estudou na Vassar College, entre os anos de 1930 e 1934 (PAGE, 2014).

Muitos anos depois, em Saratoga Springs, Nova York, envia carta endereçada ao amigo Frankenberg, datada de 10 de novembro de 1950, na qual adiciona uma cópia datilografada de The Owl's Journey e um desenho de um coelho com uma coruja cravada nas costas. Esses animais, mais adiante, fariam parte do poema The Armadillo, enviado para publicação em 1957. O conjunto de manuscritos encontra-se na pasta 64.10 da Vassar College. Nessa carta, Bishop inclui um desenho:

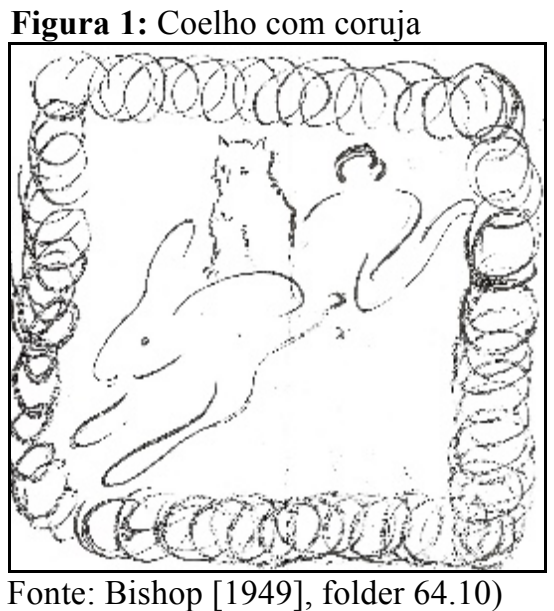


Segundo Anastácio (1999), um dos possíveis títulos de The Armadillo seria From a Letter, o que indicia que Bishop buscou, a princípio, fazer uma alusão em seu poema àquela carta enviada ao amigo Frankenberg, anos antes. Esse fato atesta, de certa forma, que os rascunhos datados da década de 1930 seriam, de fato, um falso início para The Armadillo.

Já no Brasil, Bishop escreve um poema não publicado, intitulado St. John's Day. Esses rascunhos, também anteriores a The Armadillo, foram possivelmente escritos entre 1955 e 1956, conforme datação fornecida pela edição mais recente dos poemas de Bishop, organizada por Giroux e Schwartz (2008). Tais manuscritos podem ser localizados na Vassar College, em pastas identificadas com os números 67.6 (os três primeiros) e 73.2 (o quarto); compõem-se, portanto, de quatro fólios, sendo que os três primeiros fazem parte do que Biasi (2010) chama de fase pré-redacional. No quarto fólio encontramos um poema bem estruturado, característico da fase redacional.

Assim como The Armadillo, o poema St. John's Day é organizado em quartetos. Nele, Bishop inclui uma epígrafe com um dito popular que se refere à homenagem feita a São João no dia 24 de junho: "If St. John only knew it was his day, / He would descend from heaven \& be gay" (BISHOP, 2008 [1955], p. 238)². Para corroborar esse dito, há uma constatação ao fim do poema de que, nesse dia, o santo homenageado costuma dormir, enquanto todos celebram a sua festa:

\author{
But no prayer \\ can Wake him. Is it cowardice? \\ He sleeps, he always sleeps the solstice. \\ If he didn't his party might be gayer (BISHOP, 2008 [1955], p. 239).
}

Os elementos usados nesses poemas - e presentes em The Armadillo - já vinham sendo trabalhados em cartas, como era seu costume fazer. Em junho de 1955, Bishop escreve a Anny Bauman, fazendo um relato de como os brasileiros gostam de soltar balões nas festas de São João:

Fire balloons are supposed to be illegal but everyone sends them up anyway and we usually spend St. John's night and the nights before and after watching the balloons drifting right up the mountain towards the house - there seems to be a special draught: Lota has a sprinkling system on the roof just because of them. \& They are so pretty - one's of two minds about them (BISHOP apud MILLIER, 1993 [1955], p. 275$)^{3}$.

\footnotetext{
${ }^{2}$ Se São João soubesse que este era o seu dia / Ele desceria do céu \& ficaria contente

${ }^{3}$ Balões juninos são ilegais, mas todos os soltam. Geralmente passamos a noite de São João e as noites anteriores e posteriores assistindo aos balões flutuarem perto da montanha em direção à casa, e parece que há um projeto
} 
Não somente o elemento balão foi tema de suas cartas, mas também a catástrofe que ele pode causar quando se choca contra o solo. Não raro, esses balões caíam nas florestas, prejudicando a fauna e a flora. Soltar balões foi uma prática tradicional no Brasil, especialmente no período de São João, até o ano de 1998, quando foi sancionada a Lei $\mathrm{n}^{\circ}$ 9.605, que os tornara ilegais. Bishop menciona para a amiga o perigo desses artefatos, embora revele que não abria mão de apreciá-los.

Em maio de 1956, Bishop escreve para Marianne Moore a respeito dos animais que habitavam uma dessas matas, situada próximo à casa onde morou em Petrópolis, com Lota de Macedo Soares:

After all this time, I've just found out we have armadillos here - I see one crossing the road in the headlights at night, with his head and tail down - very lonely and glisteny. There's also a kind of small owl that sits in the road at night - I had to get out and shoo one away from the front of the car last night. They have large eyes; when they fly off look exactly like pin-wheels - black and white (BISHOP apud MILLIER, 1993 [1956], p. 275) ${ }^{4}$.

A recorrência de temas nos diversos textos de Elizabeth Bishop, sejam eles em prosa, sejam em verso, parece estar relacionada com a busca por imagens mais precisas, o que contribui para construção de poemas descritivos os quais adotam a paisagem e seus elementos como imagens que preponderam em seus escritos poéticos.

Em outra carta datada de 24 de junho de 1955, escrita a Anny Bauman, Bishop comenta sobre o tempo ruim, que prejudica, de certa forma, os festejos juninos e o espetáculo promovido pelos balões: "This is Saint John's Day [...]. It is pouring rain which is too bad because it's a day for fireworks and bonfires, etc. - but very good, really, because there may not be so many forest fires and accidents" (BISHOP apud COSTELLO, 1991 [1955], p. 76) .

especial: Lota tem um sistema de aspersão no telhado por causa deles. São muito bonitos - uma entre duas pessoas prestam atenção a eles.

${ }^{4}$ Depois de todo esse tempo, eu descobri que temos tatus aqui - eu vi um atravessando a estrada iluminado pelos faróis à noite, com cabeça e rabo baixos - muito solitário e cintilante. Há também um tipo de coruja pequena que fica na estrada à noite - a noite passada eu tive que sair e espantar uma da frente do carro. Elas têm olhos grandes e, quando voam, parecem cataventos preto e branco.

5 Este é o dia de São João [...]. Está chovendo, o que é muito ruim porque este é um dia para se soltar balões juninos e fogos de artifício, etc. - mas, por outro lado, é bom porque, assim, pode não haver tantos incêndios e acidentes nas florestas. 
Embora essa imagem não apareça no poema final, podemos observá-la em seus rascunhos, notadamente no sexto fólio do dossiê estudado, quando há uma remissão ao tempo, com a indicação de que era um dia chuvoso: "on rain $X^{6}$, like hearts",

No mesmo ano, em agosto, Bishop envia nova carta a Bauman, dessa vez descrevendo os resultados da devastação do fogo causado pelos balões: "Now all our scenery, all the mountains, are burned black with what trees survived all singed pale yellow, or white - it looks exactly like the negative of a photograph, awful, but beautiful, in a way" (BISHOP apud COSTELLO, 1991 [1955], p. 76) $)^{8}$.

O novo cenário influencia a construção da imagem da sexta estrofe. A descida do balão, provocada por um vento vindo do alto de uma montanha, "<or else a down-draught form the peak $>$ ", figura como o início de um desfecho em que o artefato retorna ao solo. Este verso, "\& quickly [come] <start> down, after us"10, é posteriormente abandonado e, assim, Bishop inclui como vítimas da catástrofe apenas seres do reino animal.

Quanto à ideia apresentada, entendemos que se relaciona com o estilo de Bishop de organizar o seu pensamento. Por vezes, o jogo dialético prevalece, como é o caso do referido poema. É como se, depois de apreciar a subida para prestar homenagem ao santo, do qual não se menciona o nome, o balão retornasse e viesse atrás de nós ou dos animais da floresta para uma prestação de contas.

O poema é construído, desse modo, em torno de jogos de oposição entre o espaço natural e o técnico, este último representado no poema pelo balão, que traz consequências para o que Santos (2014 [1996], p. 38) denomina tecnoestrutura. Em suas palavras, a tecnoestrutura é o "resultado das inter-relações essenciais do sistema de objetos técnicos com as estruturas sociais e as estruturas ecológicas".

No poema, o resultado dessa interação é representado pelo incêndio na floresta, causado pela queda do balão. Nesse sentido, podemos dizer que o espaço natural é o que redefiniu a utilização ou a existência de tais objetos técnicos. Desse modo, embora o balão junino tenha servido, por algum tempo, como meio de entretenimento, acabou sendo

\footnotetext{
${ }^{6}$ Símbolo usado na transcrição para indicar palavra ilegível.

${ }^{7} \mathrm{Na}$ chuva, como corações.

${ }^{8}$ Agora todo o nosso cenário, todas as montanhas estão queimadas, pintadas de preto com o que restou de algumas árvores, tudo chamuscado de um amarelo descorado, ou de branco - está parecendo exatamente um negativo de uma fotografia. Medonho mas, de certo modo, bonito.

${ }^{9}$ Ou mesmo uma corrente de ar vinda de um pico.

${ }^{10} \&$ rapidamente $[\mathrm{vem}]<$ começa $>$ para baixo, atrás de nós.
} 
considerado um objeto proibido por oferecer perigo não somente a animais e a florestas, mas também ao próprio ser humano.

No MS. 6, podemos observar acréscimos e supressões, movimentos que indiciam uma testagem de palavras, além da repetição de vocábulos como no verso " \& [steadily steadily] dwindle, dwindle steadily <solemnly,>"11. Há o acréscimo da palavra "solenemente," fazendo uma alusão à homenagem ao santo, como se o balão, no momento que retorna ao solo, estivesse ainda lhe prestando reverência.

No MS. 7, Bishop reescreve as estrofes que ela já havia, de algum modo, testado nos manuscritos um, dois e três. Entre as segunda e terceira estrofes, há um espaço em branco, marcado por travessões, como se ali a escritora quisesse incluir mais um quarteto, o qual nunca seria escrito. Abaixo da terceira estrofe, com recuo da margem esquerda, reescreve as outras duas estrofes já trabalhadas: a oitava e a nona.

Nesse fólio, o título volta a ser "[Minor Catastrophe]”. Quanto ao santo, caracterizado no MS. 6 como "minor" (menor), reaparece adjetivado com a palavra "some" (algum); continua, desse modo, usando um termo que minimiza a importância do santo, já que não lhe é dado um nome. Nesse sentido, Bishop traz para o poema a ironia que é própria de seus textos.

Poderíamos, então, ler esse fragmento como indicativo de que a insignificância do santo em face da catástrofe ocorrida por motivo de sua homenagem é, nessa etapa da escritura, transferida para o título "[Minor Catastrophe]"; opera-se, então, uma inversão do peso que se esperaria que fosse dado a cada situação. Na última versão do poema, embora o verso "still honored in these parts"12 arrefeça, de alguma forma, o sentido da menor importância dada ao santo em todo o prototexto, ele ainda não recebe o lugar de destaque dado pela cultura brasileira.

Em poema não publicado, St. John's Day, classificado nesta pesquisa como um falso início de The Armadillo, Bishop inclui a epígrafe: "If St. John only knew it was his day / He would descend from heaven \& be gay" "13. Com esse dito antigo, chama a atenção para o que seria a atitude do santo a respeito desse dia, o que é reforçado pela última estrofe: "But no, no

\footnotetext{
${ }^{11}$ (\& [firme firme] diminuindo, diminuindo com firmeza $<$ solene, $>$ ).

${ }^{12}$ Ainda homenageado nessas partes.

${ }^{13}$ Se São João soubesse que este era o seu dia / Ele desceria do céu \& ficaria contente.
} 
prayer / can wake him. Is it cowardice? / He sleeps, he always sleeps away the solstice. If he didn't his party might be gayer" ${ }^{\prime 14}$.

No MS. 5, aparecem dois títulos, lado a lado, suprimidos: "[Minor Tragedy]" e "[The Owl's Nest]", logo substituídos por "<From a Letter >". A respeito do título "Minor Tragedy", destacamos a prática de Bishop de abordar temas que envolvem a dor de forma impassível. Segundo Brandão (2013), os poemas descritivos de Bishop buscam retratar um mundo prévio à sua própria existência. A essa tendência, relaciona-se a supressão da presença daqueles observadores, marcada no MS. 4. Seres humanos reaparecem apenas no MS 6, na construção de uma imagem que apresenta esses possíveis observadores como vítimas da catástrofe causada pelo balão junino, representados pelo pronome oblíquo " $u s$ ".

Novamente, as estrofes estão numeradas, exceto a segunda, seguida por outra com apenas um verso escrito. Abaixo dele, há três linhas em branco.

Figura 2: Esboço de verso

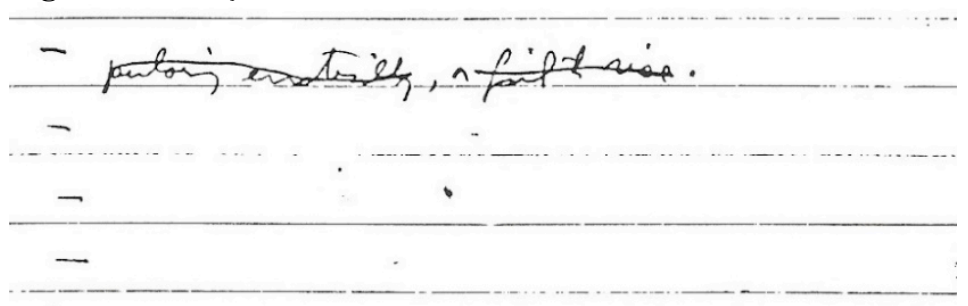

- [pulsing entirely, fail to rise]

Fonte: Bishop (1955, folder 73.2, MS. 5).

O verso "[pulsing entirely, fail to rise $] " 15$, suprimido, se alinha a uma tentativa de caracterizar o balão junino que, em seu momento de maior esplendor, pulsava mais (pulsing entirely), sendo até mesmo confundido com os planetas Marte e Vênus; entretanto, em certo momento, ao esgotar as suas possibilidades de manter-se no ar, o balão começa a perder a sua potência (fail to rise).

A rejeição desse verso parece estar relacionada com a busca por uma textualidade que, embora carregue a marca da precisão, busca meios de apresentar ao leitor uma descrição mais oblíqua e reticente, o que caracteriza a escrita literária, especialmente a dessa autora.

\footnotetext{
${ }^{14}$ Mas nenhuma, nenhuma oração / pode acordá-lo. É covardia? / Ele dorme, ele sempre dorme por todo solstício. Se ele não dormisse, sua festa seria mais alegre.

${ }^{15}$ Pulsando inteiramente, falha em sua subida.
} 
Ainda no MS. 5, surge a imagem geradora da quarta estrofe, precedida pelo número 4, indicativo da ordenação dada pela escritora para o formato final de seu poema, em relação ao qual sofre poucos ajustes. Ainda relacionando o balão chamejante aos corpos celestes, Bishop cria textualmente a situação de um dia sem vento, o que faria com que o balão permanecesse no céu, ocupando um espaço localizado no centro da Constelação do Cruzeiro do Sul.

Figura 3: Esboço de estrofe

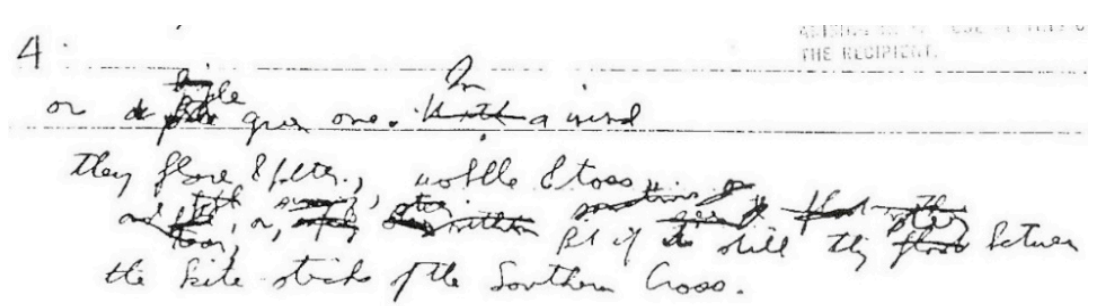

4. or [a pale] $<\mathrm{X}$ pale $>$ green one. [With] $<$ In $>$ a wind they flare $\&$ falter, wobble $\&$ toss; [and tear] $<\mathrm{X}>$, a $<\mathrm{XXX}>$ [stir within] $<$ sometimes $>$. But if it's $<\mathrm{XXXX}>$ still they glare* between the kite sticks of the Southern Cross (BISHOP, 1955, folder 73.2 MS. 5).

Fonte: Bishop (1955, folder 73.2, MS. 5).

Além da criação da estrofe acima, são revisadas nesse manuscrito as estrofes primeira, segunda e terceira, com poucos movimentos de gênese.

No MS. 6, Bishop faz revisão das segunda e terceira estrofes, além de desenvolver a quinta. Nessa fase da escritura, não há preocupação em preservar os quartetos, mas em testar palavras, a fim de encontrar o melhor ritmo para o poema. Na primeira estrofe, acrescenta a palavra "minor" para caracterizar o santo homenageado, que tem boa reputação naquele lugar, que ela qualifica como distante: "well thought-of in these < distant> parts"16.

Figura 4: Esboço de estrofe

\footnotetext{
${ }^{16}$ Com boa reputação nesse lugar distante.
} 


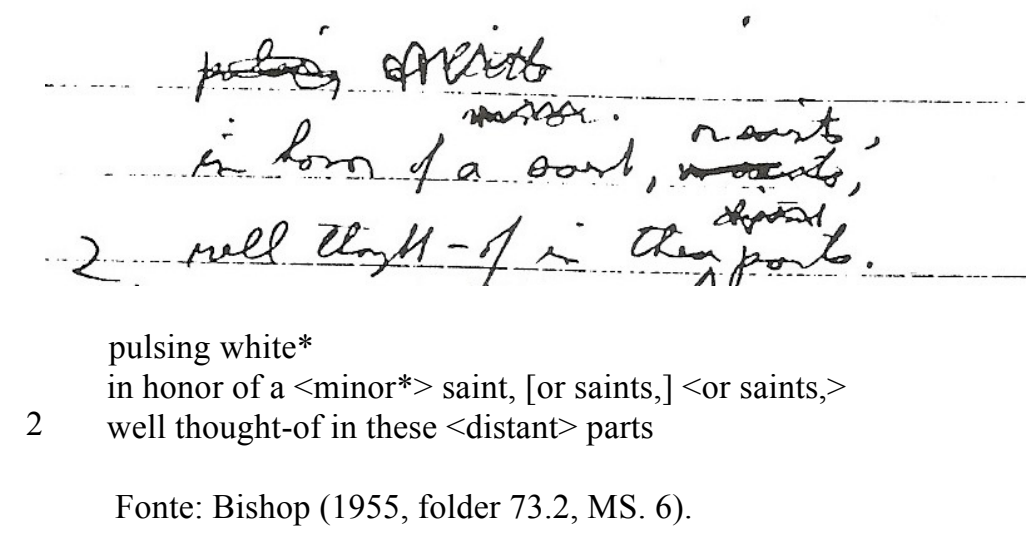

Apesar de, no momento da escrita a autora, já viver no Brasil por cinco anos, o sintagma usado para retratar o espaço brasileiro é "in these <distant> parts" ${ }^{\text {"17 }}$, o que revela não somente a focalização de um público leitor específico, o americano, mas que o sentimento de posse relacionado ao território material pode estar dissociado de outros níveis da territorialização, como dos simbólico, econômico e emocional. Não raro, Bishop utiliza, em seus textos, sendo eles ficcionais ou não, marcas que identificam um leitor situado no contexto de seu país de origem, como é o caso do fragmento em questão.

Esses vestígios apontam para uma experiência territorial efetivada em vários níveis. O fato de Bishop escolher o Brasil como território material e adotar os Estados Unidos como território simbólico, econômico e afetivo, parece ser o resultado de uma fuga dos locais onde a intelectualidade ou a vida urbana se constituem. Opta então por viver em um espaço e voltar a sua escrita para outro.

Torna-se oportuno mencionar que Bishop nunca falou o português durante o tempo em que morou no Brasil. Em 1966, quando perguntada em entrevista sobre a sua relação com a língua portuguesa, ela afirma: "Eu não tenho o costume de ler em português - apenas jornais e alguns livros. Depois de todos esses anos, sou como um cachorro. Compreendo tudo o que me dizem, mas não me comunico muito bem" (BISHOP, 2013 [1966], p. 43).

Quando, em 21 de setembro de 1956, a editora The New Yorker envia para Bishop uma prova tipográfica do poema, Bishop recebe sugestões para que inclua algumas alterações em seu texto, a exemplo da palavra "Brazil" no título. Acata, naquele momento, a sugestão do editor Howard Moss. A especificação de uma localidade somente aparece nessa publicação. Quando o poema reaparece, em 1965, no livro Questions of Travel, Bishop elimina quaisquer vestígios que correlacionem a sua poesia a um lugar específico.

\footnotetext{
${ }^{17}$ Nesse lugar distante.
} 
Bishop, por vezes, demonstra certa preocupação com o direcionamento que a The New Yorker pretende dar a seu trabalho, chegando a expor que não gostaria de ser reconhecida como uma poeta que só sabe falar sobre a América do Sul. Em carta enviada a Lowell, revela:

But I worry a great deal about what to do with all this accumulation of exotic or picturesque or charming detail, and I don't want to become a poet who can only write about South America, etc. - it is one of my greatest worries now - how to use everything and keep on living here, most of the time, probably - and yet be a New Englander-herring-choker-bluenoser at the same time (BISHOP apud GOLDENSOHN, 1992, p. 17) ${ }^{18}$.

Em uma tentativa de se definir, Bishop reúne signos que apontam para uma identificação com os lares do Norte: New Englander, uma pessoa nascida na Nova Inglaterra, região situada no nordeste dos Estados Unidos; e herring-choker, proveniente das províncias marítimas canadenses, ou Nova Escócia (CASSIDY; HALL, 1991, p. 980); bluenoser, um nativo do leste do Canadá, particularmente da Nova Escócia, New Brunswick ou Ilha Prince Edward (CASSIDY; HALL, 1985, p. 307).

Embora o Brasil seja o lugar no qual a autora decide viver, não se configura, porém, como um território ao qual mantenha plena identificação. Observamos que a manutenção de amigos, a fonte de renda, o direcionamento de seu trabalho e de sua voz voltam-se para a América do Norte, o que não lhe impede, entretanto, de ter o espaço brasileiro como fornecedor de subsídios para sua escrita literária. Parece que vivenciar estranhamentos constantes seria preponderante para alimentar o seu processo criativo.

Em seus papéis, notamos a existência de elementos que indiciam uma conjugação do lar real com o simbólico. A vida no Brasil (servindo como uma forma de se proteger da sociedade norte-americana a qual Bishop não se sentia capaz de enfrentar), lhe concede a sensação de bem-estar despertada não somente pela materialidade da casa, a qual chama de lar, mas também pelas relações de amizade e trabalho que pôde continuar mantendo com os seus compatriotas.

Empenhando-se em construir uma identificação para si como poeta norte-americana e, desse modo, delinear o seu público específico, Bishop começa a eliminar de seus textos as marcas que os associem ao espaço brasileiro.

A The New Yorker, entretanto, continua a insistir na identificação de Bishop com o Brasil, de modo que a autora vai buscando, cada vez mais, afastar-se daquela revista e reduzir,

\footnotetext{
${ }^{18}$ Mas eu me preocupo muito com o que fazer com todo esse acúmulo de detalhes charmosos ou pitorescos ou exóticos, e eu não quero me tornar uma poeta que só pode escrever sobre a América do Sul etc. - esta é uma das minhas maiores preocupações agora - como aproveitar tudo isso e ainda continuar morando aqui, a maior parte do tempo, provavelmente - e continuar sendo uma New Englander herring-choker-bluenoser ao mesmo tempo.
} 
tanto quanto possível, a quantidade de suas publicações, deixando de assinar os contratos de primeiras leituras, mesmo quando a revista lhe oferece privilégios.

\section{Conclusão}

O estudo do processo criativo associado a conceitos espaciais pareceu ser útil, não somente para a abordagem das práticas de escrita de Elizabeth Bishop, mas também para o entendimento de seu modo de estar no mundo. Somos então levados a acreditar que o pensamento espacializante foi a forma que Bishop assumiu para apresentar suas percepções, tanto no plano artístico quanto no real, o que pode ser depreendido de seu processo de criação e de suas cartas em que tal processo é, muitas vezes, tematizado.

Ainda no tocante ao estudo de gênese, acreditamos que cada etapa da escrita, acompanhada pelo crítico a partir de signos gravados sobre um espaço material, deve ser abordada a partir do estabelecimento de relações entre espacialidade e temporalidade, para que, desse modo, seja possível identificar os mecanismos adotados pelo escritor para a produção textual.

O prototexto, como espacialidade que permite que a história do texto seja contada, reúne tempo e espaço, os quais se apresentam como categorias indissociáveis, capazes de construir "uma teoria crítica mais flexível e equilibrada, que reenlaça a feitura da história com a produção social do espaço" (SOJA, 1993 [1989], p. 19).

Esse modo de abordar uma textualidade que toma forma e se espacializa no mundo a partir da inventividade de uma mente criadora propicia a conjugação dos eixos sintagmáticos e paradigmáticos que perpassam o texto e, dessa forma, conduz a uma leitura que entende a construção textual como realização no tempo que modifica o espaço.

O espaço, então, torna-se um dos elementos que propulsiona a criação literária a qual, por sua vez, tem o poder de modificá-lo com imagens que, no caso de Bishop em específico, podemos dizer que são pintadas com a linguagem, já que estamos diante de materiais produzidos por uma escritora que é, também, uma pintora. Assim, a criação poética, que pode se voltar para a representação de objetos e espaços do mundo real, tem o poder de gerar novos sentidos, à medida que a escrita literária reapresenta ou relê o mundo sob uma perspectiva singular.

\section{Referências}


ANASTÁCIO, Silvia Maria Guerra. O Jogo das Imagens no Universo da Criação de Elizabeth Bishop. São Paulo: Annablume, 1999, 258 p.

BARBOSA, Elisabete. A poética dos espaços na obra de Elizabeth Bishop: uma edição genética dos poemas The Armadillo e North Haven. 2016. Tese (Doutorado em Literatura e Cultura) - Programa de Pós-Graduação em Literatura e Cultura, Universidade Federal da Bahia. Salvador, $271 \mathrm{p}$.

BIASI, Pierre-Marc de. A genética dos Textos. Trad. Marie-Hélène Paret Passos. Porto Alegre: Edipucrs, 2010, 174 p.

BISHOP, Elizabeth. Notes and notebooks of drafts, dreams, and other observations. Drafts: Armadillo. Elizabeth Bishop Collection, Vassar College, Poughkeepsie, New York, [1955], folder 73.2 .

BISHOP, Elizabeth. Published Poetry. The Armadillo. Elizabeth Bishop Collection, Vassar College, Poughkeepsie, New York, [1957], folder 113.13.

BISHOP, Elizabeth. Published Poetry. The Owl's Nest [The Armadillo]. Elizabeth Bishop Collection, Vassar College, Poughkeepsie, New York, [1957], folder 57.13.

BISHOP, Elizabeth. St. John's Day. In: BISHOP, Elizabeth. Poems, prose, and letters. New York: The Library of America, 2008 [1955], p 238-239.

BISHOP, Elizabeth. Uma entrevista com Elizabeth Bishop. Washington, Shenandoah, n. 17, 1966. Entrevista a Ashley Brown. Trad. Carolina Barcellos. In: MONTEIRO, George (org.). Conversas Com Elizabeth Bishop. São Paulo: Autêntica, 2013 [1966], p. $41-53$.

BISHOP, Elizabeth. Unpublished Poetry. St. John's Day. Elizabeth Bishop Collection, Vassar College, Poughkeepsie, New York, [1955-1956], folder 67.6.

BISHOP, Elizabeth. Unpublished Poetry. The Owl's Journey. Elizabeth Bishop Collection, Vassar College, Poughkeepsie, New York, [1949-1950], folder 64.10.

BOLTER, Jay. Writing as technology. In: Writing space. Computers, hypertext, and the remediation of print. LEA: Mawhah, 2001, p. 14-26.

CASSIDY, Frederic; HALL, Joan. Dictionary of American Regional English. Cambridge, Ma: Belknap Press of Harvard University Press, 1985. (V. 1: Introduction and A-C).

CASSIDY, Frederic; HALL, Joan. Dictionary of American Regional English. Cambridge, Ma: Belknap Press of Harvard University Press, 1985. (V. 2: D-H).

COSTELLO, Bonnie. Elizabeth Bishop. Questions of Mastery. Cambridge: Harvard University Press, 1991 [1974], p. 210.

FOUCAULT, Michel. Linguagem e literatura, por Michel Foucault. In: MACHADO, Roberto. Foucault, a filosofia e a literatura. Rio de Janeiro: Jorge Zahar Editor, 2000 [1964], p. 137-175. 
FOUCAULT, Michel. Outros espaços. In: MOTTA, Manoel Barros da (org.). Michel Foucault. Estética: Literatura e pintura, música e cinema. Trad. Inês Barbosa. Rio de Janeiro: Forense Universitária, 2009 [1984], p. 411-422.

GIROUX, Robert; SCHWARTZ, Lloyd (orgs.). Elizabeth Bishop. Poems, prose, and letters. New York: Literary Classics of the United Stated, 2008.

GOLDENSOHN, Lorrie. Elizabeth Bishop: The Biography of a Poetry. New York: Columbia University Press, 1992, 306 p.

GRÉSILLON, Almuth. Elementos de crítica genética. Trad. Patrícia Reuillard et al. Porto Alegre: UFRGS, 2007 [1994], 335 p.

MILLIER, Brett. Elizabeth Bishop. Life and the Memory of It. Berkeley: University of California Press, 1993, 602 p.

PAGE, Bárbara. Home, wherever that may be: poems and prose of Brazil. In: CLEGHORN, Angus; ELLIS, Jonathan (orgs.). The Cambridge Companion to Elizabeth Bishop. New York: Cambridge University Press, 2014, p. 124-140.

SALLES, Cecília. Redes da criação. Construção da obra de arte. São Paulo: Horizonte, 2006, $176 \mathrm{p}$.

SANTOS, Milton. A natureza do espaço. São Paulo: Edusp, 2014 [1996], 384 p.

SOJA, Edward. Geografias pós-modernas. A reafirmação do espaço na teoria social crítica. Trad. Vera Ribeiro. Rio de Janeiro: Zahar, 1993 [1989], 324 p. 